(Paper No. 4095.)

\title{
"The Connection between the Elastic Phenomena exhibited during Slow Reversals of Stress and the Ultimate Endurance of Steel."
}

By William Charles Poppleweld, M.Sc., Assoc. M. Inst. C.E.

Is this Paper are described the results of a number of experiments undertaken with a view to ascertain how far the ultimate endurance of iron and steel under rapid reversals of stress can be suggested by experiments carried out in an ordinary testing machine with slowly applied loads. These experiments, carried out in the Materials Testing Laboratory of the Manchester School of Technology during intervals in teaching work, have taken several years to complete. They consist of the four sets detailed below, which, taken in order, lead up to the final conclusions:-

1. A repetition, with iron and steel in common use at the present time, of some of Bauschinger's experiments on the effect of slow reversal of stress in determining the position of elastic limits.

2. Finding the position of artificial elastic limits following the repeated application of stresses having the same values in tension and compression.

3. Experiments based on the results of the last set, in which a possible limiting stress was found by means of slow reversals under different loads.

4. Endurance tests carried to fracture on rotating beams of the same material as were used in 3.

The various series of experiments which have been carried out for the purpose of ascertaining the stress which a given material is capable of withstanding for an unlimited number of repetitions are now fairly generally known. Wöhler, the pioneer in this field of research, obtained results and deduced laws which are probably still the most important and have formed the basis upon which most of the latter resen'ches have been carried out. This, however, hardly 
applies to Bauschinger, who, besides repeating and comparing many of Wöhler's experiments, sought, by examining in greater detail than previously had been done the behaviour of bars when subjected to slow reversals of stress in a testing machine, to arrive at a possible explanation of the Wöhler results, and to establish some kind of connection between the two kinds of experiments.

The results which Bauschinger obtained when experimenting upon iron and steel bars in a testing machine and using accurate extensometers, are referred to by Dr. Unwin, in his "Testing of Materials," as possibly affording some explanations of the Wöhler phenomena. In more than one of the discussions following recent Papers dealing with repetitive tests, Dr. Unwin has advocated a more complete examination of what may be called the Bauschinger phenomena, and has always insisted that the solution of some of the more important effects of repetitive stress are to be found in this direction.

\section{The Author's Repetition of Bauschinger's Experiments.}

The behaviour of iron and steel under slow reversals of stress was first investigated by Bauschinger about 1886.1 The general results of his work are now fairly well known and need not, therefore, be referred to further.

\section{The Author's Experiments.}

The results about to be described relate to experiments on three bars of different material carried out on Bauschinger's plan of varying the maximum stresses as desired until the "natural limits" were finally reached.

The materials used were three in common use at the present time, namely, a high carbon tool-steel (referred to below as cast steel), a low carbon structural steel and an average wrought iron. The following are their commercial properties :-

Taber I.-Comyercial Tests of the Three Materials used.

\begin{tabular}{lc|c|c|c}
\hline & & Cast Steel. & Mild steel. & Wrought Iron. \\
\hline Yield loint. & Tons per sq. in. & $22 \cdot 25$ & $15 \cdot 70$ & $16 \cdot 32$ \\
Maximum stress. Tons per sq. in. & $47 \cdot 90$ & $25 \cdot 40$ & $23 \cdot 60$ \\
Percentage elongation on 10 inches & $7 \cdot 2$ & $28 \cdot 4$ & $21 \cdot 0$ \\
Percentage reduction in area . & $22 \cdot 2$ & $70 \cdot 0$ & $42 \cdot 0$ \\
\hline
\end{tabular}

I W. C. Unwin, "The Testing of Materials of Construction." Londun, 1910. 
The specimens were turned of the form in Fig. 1, which shows them in their grips. In the earlier experiments the loads were transmitted in compression through the flat ends of the bars, but later this plan was discarded in favour of the steel balls shown in the Figure to obtain a greater uniformity in the distribution of the stress.

The area of cross section of each bar was 2.06 square inches, and the length upon which elastic measurements were taken 10 centimetres. The experiments were carried out in the 50-ton horizontal Buckton testing-machine in the Materials Testing Laboratory of the Manchester School of Technology. The longitudinal strains were measured by a Martens mirror extensometer, giving direct readings to the nearest. $\frac{1}{1+(1,0)}$ inch. With this instrument two separate readings are given, one on the near face of the bar and the other on the face farther from the observer. These provide a mean reading on a plane through the observer and the axis of the

Fig. 1.

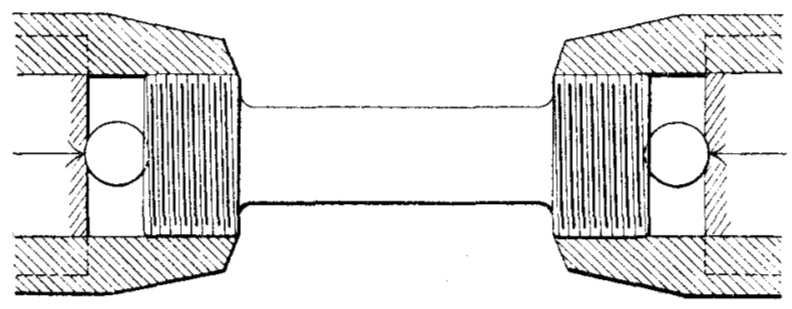

specimen. When the experiments were begun the intention was to load each specimen in question with alternating tensile and compressive stresses. In each application the stress was to be increased gradually and extensometer readings taken throughout at uniform increments of load. By watching the increments of strain as the test proceeded, the elastic limit was to be found, the load carried a little beyond this and then removed. The specimen was to be reloaded in the same way with the opposite kind of stress and so on. With some exceptions this scheme was carried out as intended.

The readings taken during the first loading of the mild steel bar are shown plotted on Fig. 2. Here the mean readings are plotted first and show a straight line up to the limit load. The separate readings for the right and left telescopes are also plotted, showing, by the nearness of their angles of slope, an approximate equality in the intensities of stress at the back and front of the bar.

The "limit stress" referred to here is the "proportional limit." 
By this is meant the point beyond which the strain ceases to be proportional to the stress. This is found either by an inspection of the Table of increments or is taken as the tangent point of the plotted graph.

Strictly speaking the "elastic limit" stress is that up to which there is no set remaining after the removal of the load, but it has

Fig. 2 .

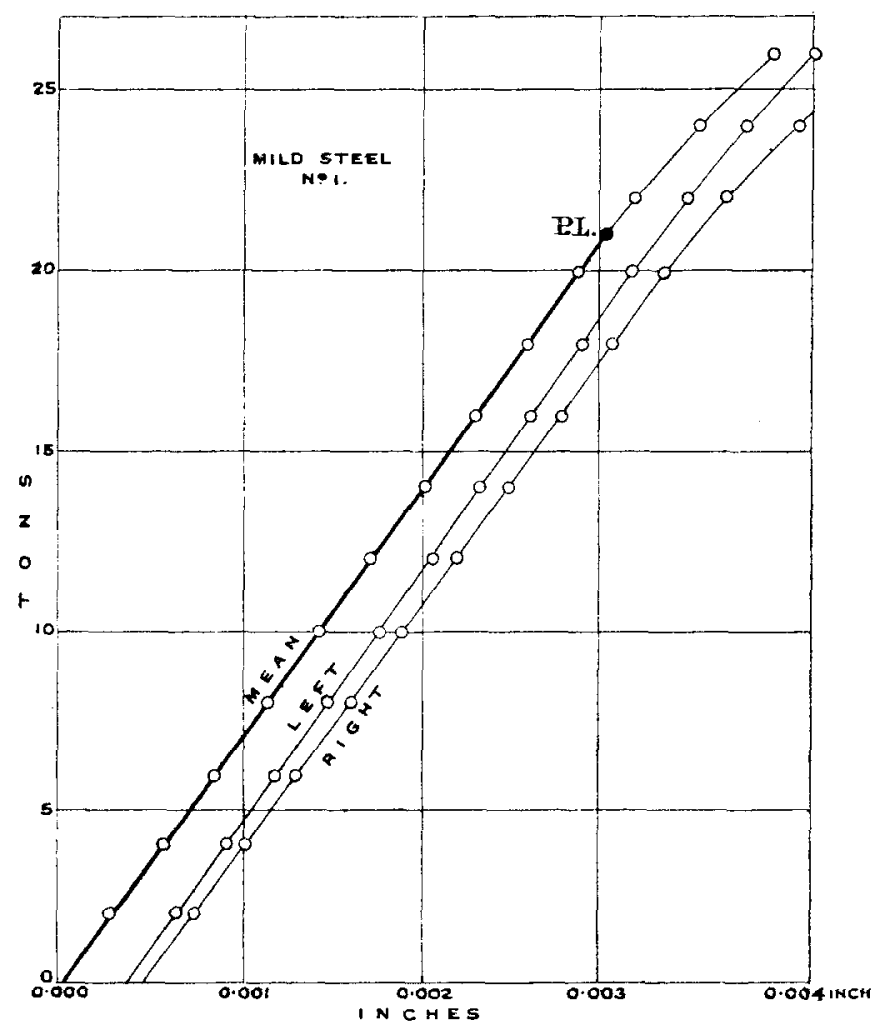

been shown that this point, when determined with instruments having a high degree of precision, practically coincides with the "proportional limit." In order to obviate the removal of the load after each reading, the elastic limit referred to was the " proportional limit" found in the manner described. In the case quoted it will be seen that the load, after passing the "limit," was carried to 26 tons, or 12.62 tons per square inch, and then removed. After 
finding the limit and carrying the load a little farther, the general plan was to release the load, reload the bar under the reverse stress, and carry on as before. This reverse loading was either done at once or, as was more usual, the bar was placed where it

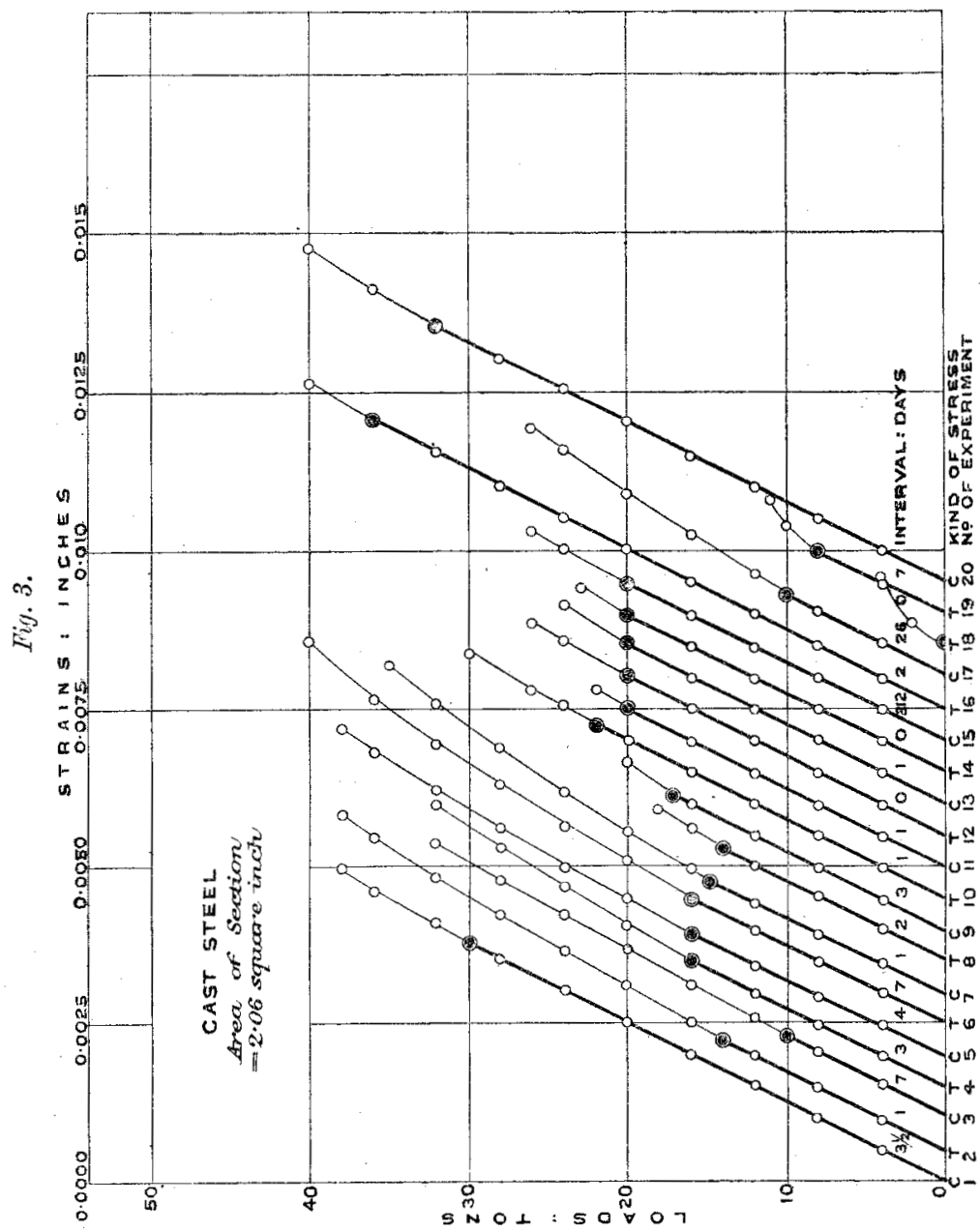

could remain at a fairly uniform temperature, and the experiment repeated under reversed stress when opportunity offered.

The results of these experiments are contained in the following Tables of figures and plotted diagrams. The curves of load and mean strain are shown in Figs. 3, 4 and 5. The strains for differ- 
ences of load of 4 tons are indicated by small circles. A blackened circle shows the "limit" point.

The stresses corresponding to these limit loads are given also in Tables II, III and IV.

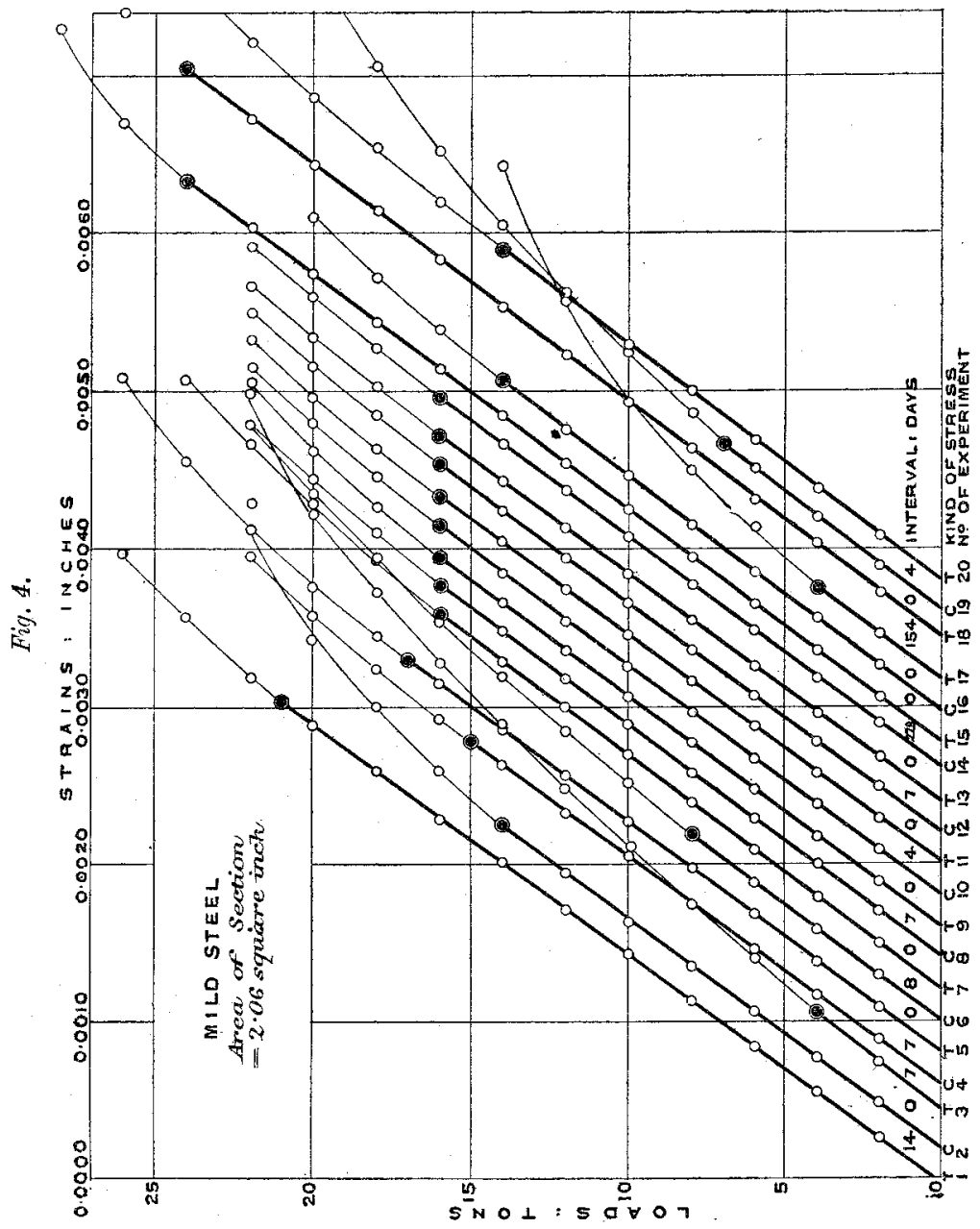

An inspection of the plotted curves on Figs. 3, 4 and 5 shows that the limit changes its position in the case of any one bar through a range extending from a stress very little below the maximum imposed to nearly zero. There is a general similarity in 
its movements for all the bars as the alternate loadings take place. These changes will be seen to be similar to those obtained by Bauschinger, and take place during the loading of all the three

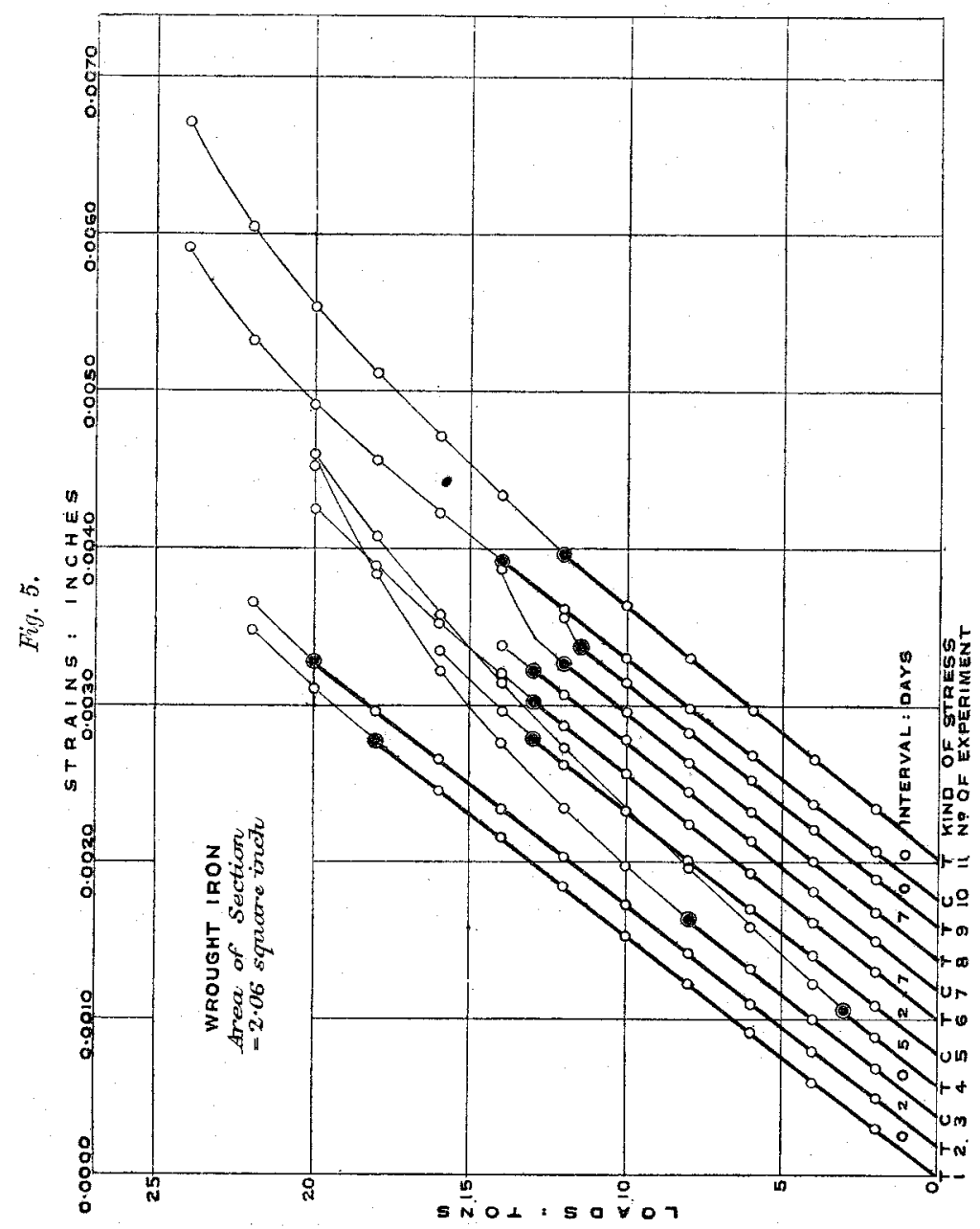

bars experimented upon. The mild steel perhaps gives the most perfect series.

Several special points arising from these results may be noted.

Cast Steel. (Table II.) - In the case of No. 3 it is very probable that the limit is lower than given, possibly at zero. In Nos. 2, 5, 
1apers.] AND TILE LITIMATE ENDURANCE OF STEEL.

Tamle II.--Rhsults of Expherments on Cast Sther Bar.

\begin{tabular}{|c|c|c|c|c|c|}
\hline \multirow{2}{*}{$\begin{array}{c}\text { Number } \\
\text { of } \\
\text { Experiment. }\end{array}$} & \multirow{2}{*}{$\begin{array}{c}\text { Interval } \\
\text { between } \\
\text { Experiments. }\end{array}$} & \multicolumn{2}{|c|}{ Proportional Limit. } & \multicolumn{2}{|c|}{ Maximum Stress. } \\
\hline & & Teusion. & Compression. & Tension. & Compression. \\
\hline 1 & $\left\{\begin{array}{c}\text { Days. } \\
\text { Original } \\
\text { condition }\end{array}\right\}$ & $\begin{array}{c}\text { Tous per } \\
\text { square Ineh. } \\
\text {. }\end{array}$ & $\begin{array}{c}\text { Tous per } \\
\text { Siluare Inch. } \\
11.08\end{array}$ & $\begin{array}{c}\text { Tons per } \\
\text { Sipare Inch. } \\
\ldots\end{array}$ & $\begin{array}{c}\text { Tons per } \\
\text { Scunre loch. } \\
15 \cdot 46\end{array}$ \\
\hline 2 & $3 \frac{1}{2}$ & $6 \cdot 80$ & .. & $18 \cdot 46$ & .. \\
\hline 3 & 1 & .. & $4 \cdot 85$ & .. & $15 \cdot 53$ \\
\hline 4 & 7 & $7 \cdot 77$ & .. & $15 \cdot 53$ & .. \\
\hline 5 & 3 & .. & $7 \cdot 77$ & .. & $18 \cdot 46$ \\
\hline 6 & 4 & $7 \cdot 77$ & .. & $19 \cdot 42$ & .. \\
\hline 7 & 7 & .. & $7 \cdot 30$ & .. & $17 \cdot 00$ \\
\hline 8 & 1 & $6 \cdot 80$ & .. & $8 \cdot 75$ & .. \\
\hline 9 & 2 & .. & $8 \cdot 25$ & .. & $9 \cdot 71$ \\
\hline 10 & 3 & $10 \cdot 68$ & .. & $14 \cdot 56$ & .. \\
\hline 11 & 1 & .. & $(9 \cdot 71)$ & .. & $10 \cdot 68$ \\
\hline 12 & 1 & $(9 \cdot 71)$ & .. & 1262 & .. \\
\hline 13 & At once & .. & $(9 \cdot 71)$ & .. & $11 \cdot 65$ \\
\hline 14 & 1 & $(9 \cdot 71)$ & .. & $11 \cdot 15$ & .. \\
\hline 15 & At once & .. & $(9 \cdot 71)$ & .. & $12 \cdot 62$ \\
\hline 16 & 212 & 1747 & .. & $20 \cdot 63$ & .. \\
\hline 17 & 2 & .. & $4 \cdot 61$ & .. & $12 \cdot 62$ \\
\hline 18 & 26 & 0.00 & .. & $4 \cdot 37$ & .. \\
\hline 19 & At once & $3 \cdot 89$ & .. & $5 \cdot 83$ & $5 \cdot 83$ \\
\hline 20 & 7 & .. & $15 \cdot 53$ & .. & $19 \cdot 42$ \\
\hline
\end{tabular}

In Tables II, III and IV the figures enclosed in brackets are those of Bauschinger's "natural elastic limits."

6 and 7 the limit is seen to be in the neighbourhood of 16 tons per square inch, and the maximum taken up to 38 tons and yet there is no indication of a yield point. At first sight this is surprising, and seems to show that this point is much more stable than the limit. The result of $(20)$, where the limit, after an interval of 
Table III.-Results of Experiments on Mild Steel Bar.

\begin{tabular}{|c|c|c|c|c|c|}
\hline \multirow{2}{*}{$\begin{array}{c}\text { Number } \\
\text { of } \\
\text { Experiment. }\end{array}$} & \multirow{2}{*}{$\begin{array}{c}\text { Interval } \\
\text { between } \\
\text { Experiments. }\end{array}$} & \multicolumn{2}{|c|}{ Proportioual Limit. } & \multicolumn{2}{|c|}{ Maximum stress. } \\
\hline & & T'ension. & Compression. & Tension. & Compression. \\
\hline & Days. & $\begin{array}{l}\text { Tons per } \\
\text { Square Inch. }\end{array}$ & $\begin{array}{l}\text { 'Tons per } \\
\text { square Inch. }\end{array}$ & $\begin{array}{c}\text { Tons per } \\
\text { square Iuch. }\end{array}$ & $\begin{array}{l}\text { 'Lons per' } \\
\text { square Incil. }\end{array}$ \\
\hline 1 & $\left\{\begin{array}{c}\text { Original } \\
\text { condition }\end{array}\right\}$ & $10 \cdot 20$ & $\because$ & $12 \cdot 62$ & . \\
\hline 2 & 14 & .. & $6 \cdot 80$ & .. & $10 \cdot 69$ \\
\hline 3 & At once & $1 \cdot 94$ & . $\quad$. & $10 \cdot 69$ & .. \\
\hline 4 & 7 & .. & $7 \cdot 28$ & .. & $10 \cdot 69$ \\
\hline 5 & 7 & $8 \cdot 25$ & .. & $12 \cdot 62$ & .. \\
\hline 6 & At once & .. & $3 \cdot 88$ & .. & $10 \cdot 69$ \\
\hline 7 & 8 & $(7 \cdot 76)$ & .. & $10 \cdot 69$ & .. \\
\hline 8 & At once & .. & $(7 \cdot 76)$ & .. & $10 \cdot 69$ \\
\hline 9 & 7 & $(7 \cdot 76)$ & .. & $10 \cdot 69$ & .. \\
\hline 10 & At once & .. & $(7 \cdot 76)$ & .. & $10 \cdot 69$ \\
\hline 11 & 4 & $(7 \cdot 76)$ & .. & $10 \cdot 69$ & .. \\
\hline 12 & At once & . & $(7 \cdot 76)$ & .. & $10 \cdot 69$ \\
\hline 13 & 7 & $(7 \cdot 76)$ & .. & $10 \cdot 69$ & .. \\
\hline 14 & At once & . & $(7 \cdot 76)$ & . & $10 \cdot 69$ \\
\hline 15 & 229 & $11 \cdot 65$ & $\therefore$ & $13 \cdot 60$ & .. \\
\hline 16 & At once & .. & $6 \cdot 80$ & .. & $9 \cdot 71$ \\
\hline 17 & $"$ & $1 \cdot 91$ & . & $9 \cdot 71$ & .. \\
\hline 18 & 154 & $11 \cdot 65$ & .. & $14 \cdot 56$ & .. \\
\hline 19 & At once & . & $3 \cdot 40$ & .. & $11 \cdot 65$ \\
\hline 20 & 4 & $6 \cdot 80$ & .. & $11 \cdot 65$ & .. \\
\hline
\end{tabular}

only 7 days, is seen to have been raised from $3 \cdot 89$ to $15 \cdot 53$ tons per square inch, appears to be abnormal.

Mild Steel. (Table III.)-Greater precision in the measuring instruments used would probably have shown the limit of (3) to have been lower.

Wrought Iron. (Table IV.)-After the long interval the limit of (8) would appear abnormal. 
Table IV.-Results of Experiments on Wrought Iron.

\begin{tabular}{|c|c|c|c|c|c|}
\hline \multirow{2}{*}{$\begin{array}{c}\text { Number } \\
\text { of } \\
\text { Experiment. }\end{array}$} & \multirow{2}{*}{$\begin{array}{c}\text { Interval } \\
\text { between } \\
\text { Experiments. }\end{array}$} & \multicolumn{2}{|c|}{ Proportional Limit. } & \multicolumn{2}{|c|}{ Maximum Stress. } \\
\hline & & Tension. & Compression. & Tension. & Compression. \\
\hline & Days. & $\begin{array}{c}\text { Tons per } \\
\text { Square Ineh. }\end{array}$ & $\begin{array}{c}\text { Tous per } \\
\text { Square Inch. }\end{array}$ & $\begin{array}{c}\text { Tons per } \\
\text { Square Inch. }\end{array}$ & $\begin{array}{c}\text { Tons per } \\
\text { Square Inch. }\end{array}$ \\
\hline 1 & $\left\{\begin{array}{c}\text { Original } \\
\text { condition }\end{array}\right\}$ & $7 \cdot 77$ & .. & $10 \cdot 68$ & .. \\
\hline 2 & At once & $8 \cdot 74$ & . & $10 \cdot 68$ & .. \\
\hline 3 & 2 & .. & $3 \cdot 88$ & .. & $9 \cdot 71$ \\
\hline 4 & At once & $1 \cdot 46$ & .. & $9 \cdot 71$ & .. \\
\hline 5 & 5 & .. & $(6 \cdot 31)$ & .. & $7 \cdot 77$ \\
\hline 6 & 2 & $(6 \cdot 31)$ & .. & $9 \cdot 71$ & .. \\
\hline 7 & 7 & .. & $(6 \cdot 31)$ & .. & $6 \cdot 80$ \\
\hline 8 & 308 & $5 \cdot 83^{1}$ & .. & $5 \cdot 83$ & . \\
\hline 9 & 7 & $5 \cdot 83^{1}$ & $\cdots$ & $6 \cdot 31$ & .. \\
\hline 10 & At once & .. & $6 \cdot 80$ & .. & $11 \cdot 65$ \\
\hline 11 & At once & $5 \cdot 83$ & .. & $11 \cdot 65$ & .. \\
\hline
\end{tabular}

1 In these the stress was very unevenly distributed, and the maximum was clearly greater than the mean stress as given.

\section{General Deductions.}

The Tables and diagrams show that the result of alternating stresses beyond the elastic limit is to cause movements in its position through very large ranges, and a more careful inspection will show that these movements are not accidental but follow very definite laws. These laws, so far as they can be deduced from the results of the present experiments, seem to be :-

(1) Application of tensile stress above the primitive tensile limit raises the tensile limit.

That the same applies to compression is not shown directly by these experiments, but others have shown that it does so apply.

(2) Application of a stress above the limit of one kind of stress depresses the limit for the other kind.

(3) By subjecting the specimen to alternate stresses, artificially depressed limits are raised and artificially exalted limits are depressed.

(4) After several repetitions this successive raising and depression [THE INST, O.E. VOL. CXCVII.] 
results in equal limits for tension and compression. This uniform limit will be referred to hereafter as the "artificial limit."

(5) After this limit has been established, uniformity of maximum stress tends to uniformity of the limit.

(6) After a long period of rest a new limit is created, which is somewhat higher than the primitive limit, and the usual series of alternations of stress must take place before an "artificial limit" is again established.

II. Artificial Limits Developed by the Application of Repeated Stresses having the same Values in Tension and CoMpression.

The experiments in the first group may be described as repetitions of those of Bauschinger on modern materials. A consideration of the results of further experiments, made with the same bars after several years, suggested to the Author that these artificial limits, so far called "natural limits," might not always have the same values for the same material if they were not always attained in the same way.

Fig. 6 .

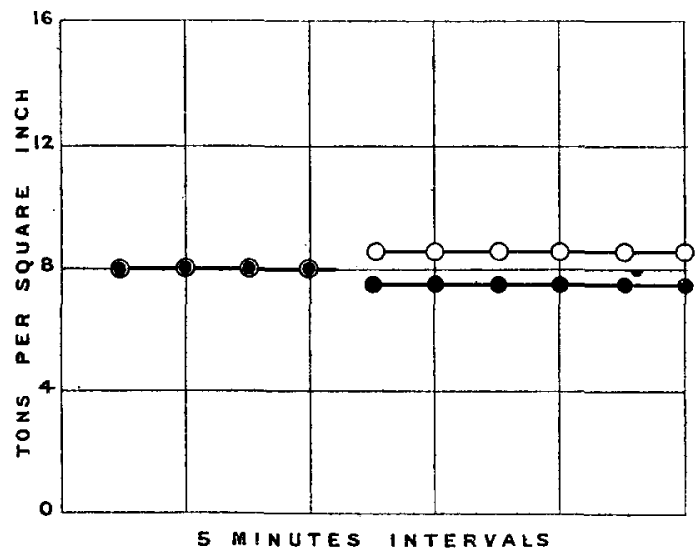

The Author made some further experiments with the object of finding out how the artificial limit is affected by the manner of its attainment. The specimen used was smaller than the former, so as to allow of the use of a Ewing ( $1 \frac{1}{4}$-inch) extensometer instead of that of Martens. By doing this, the instrument could be kept on the bar throughout the series; and, consequently, the reversals could be made much more quickly than before. 


\section{Results.}

In the diagrams Figs. 6, 7, 8, 9, 10,11, 12 and 13, each pair of circles, an open circle vertically above a blackened circle, represents

Fig. 7.

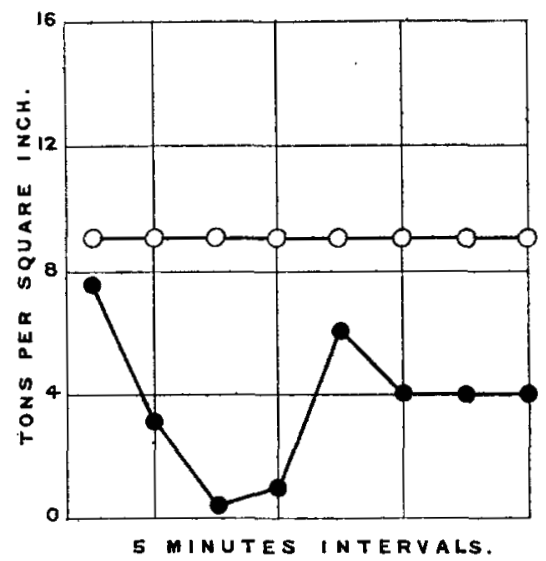

one loading of the bar. The open circles are the maximum stresses, and the blackened circles are the resulting limits. In every case the first load was one in tension.

Fig. 8.

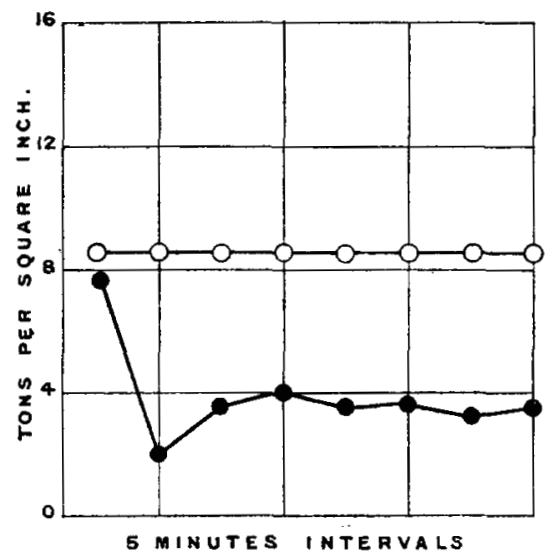

Figs. 6 and 7 belong to a pair of bars from a low-carbon steel forging. In Fig. 6 it will be seen that for the first four experiments a stress of 8 tons in tension and compression per square T 2 
inch was applied without finding a limit, but that on raising the applied load to $8 \frac{1}{2}$ tons an artificial limit of $7 \frac{1}{2}$ tons was obtained. In Fig. 7 the maximum is 9 tons per square inch, and the limit

Fiy. 9.

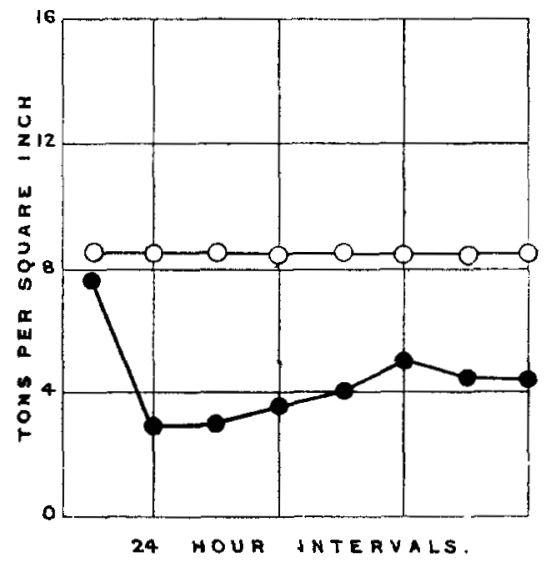

finally settles at 4 tons per square inch. These experiments confirm a suggestion that higher maximums may result in lower artificial limits.

Fig. 10.

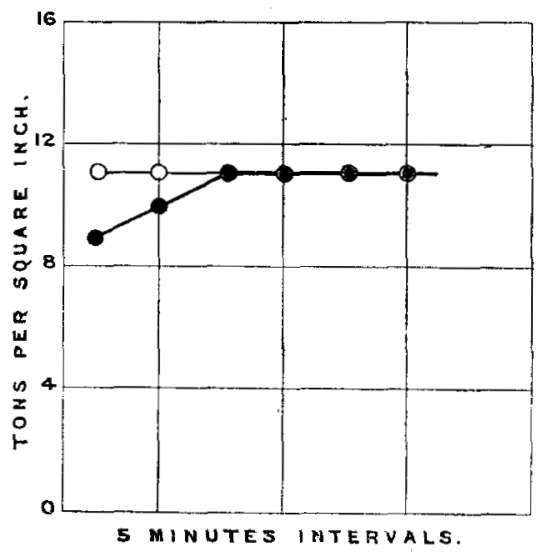

Further confirmation is found in the specimens of Figs. 10, 11 and 12, which were all turned from a bar of medium low-carbon steel and made of the same form and dimensions as the last. The 
Papers.] AND THE ULTIMATE ENDURANCE OF STEEL.

speed of loading was the same in Figs. 6, 7, 8, 10, 11 and 12, namely, there was 5 minutes' interval between the commencement of

Fig. 11.

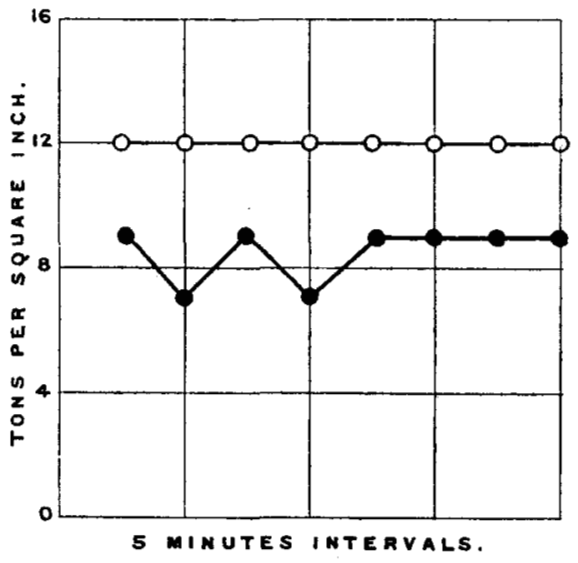

one experiment and the commencement of the next. In Figs. 8 and 9 two specimens of the same material as 6 and 7 were loaded to the same maximums, but with different speeds of loading. The

Fig. 12 .

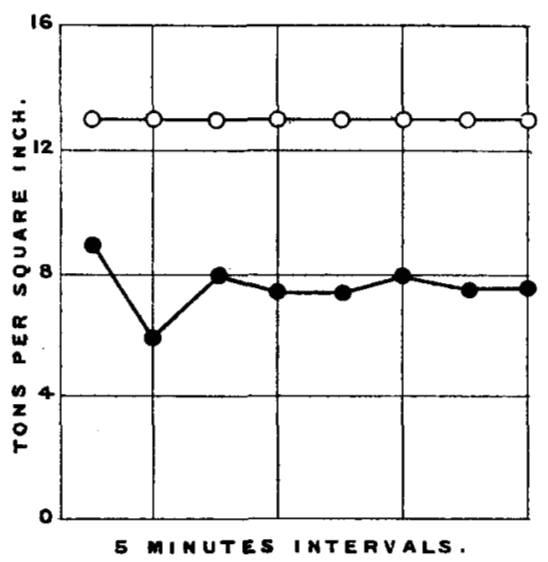

specimens on Figs. 12 and 13 were treated in the same way, namely, the same maximums, but different time-intervals, of 5 minutes and 24 hours respectively. 


\section{Conclusions.}

As regards the effect of speed of loading and repetition in determining the position of the artificial limits, there is not sufficient evidence from these experiments to warrant any definite conclusions on this point. The following may, however, be drawn :-

Fig. 13.

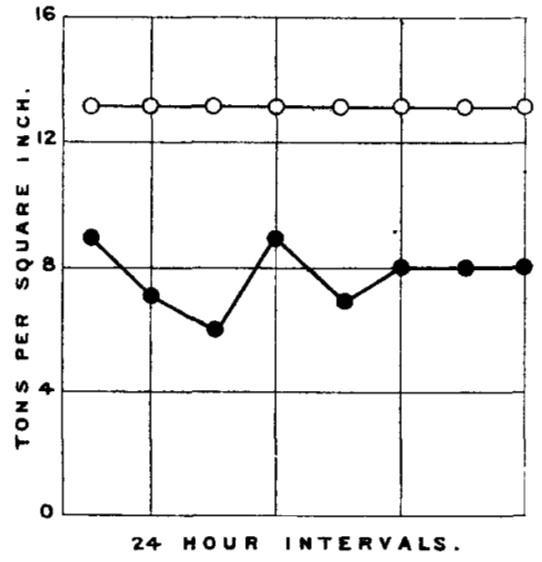

1. When a bar is subjected to a number of reversals of stress, of the same magnitudes in both directions, the artificial elastic limits will have the same values for tension and for compression.

2. The higher the applied stresses are, the lower will be the magnitudes of the consequent artificial limits.

III. Suggestion of the Limiting Stresses by a Series of Artificial Limits Produced by the Application of Slowly Applied Reversed Stresses.

The results of experiments in this group were obtained from specimens of a carbon tool-steel (referred to hereafter as cast steel), and of a low-carbon forging steel, and are typical of others obtained from mild steel. The commercial strength properties of these are :-

\begin{tabular}{|c|c|c|c|c|c|c|c|}
\hline Materiøl. & & & $\begin{array}{c}\text { Primitive } \\
\text { Limit }\end{array}$ & $\begin{array}{c}\text { Yield } \\
\text { Point. }\end{array}$ & $\begin{array}{c}\text { Tensile } \\
\text { strength. }\end{array}$ & $\begin{array}{l}\text { Elongation } \\
\text { on } 2 \text { inches. }\end{array}$ & $\begin{array}{l}\text { Reduction } \\
\text { in Area. }\end{array}$ \\
\hline Cast steel. . & 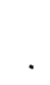 & - & $\begin{array}{l}\text { Tons per } \\
\text { Sq. In. } \\
22 \cdot 24\end{array}$ & $\cdots$ & $\begin{array}{l}\text { Tons per } \\
\text { Sq. .1n. } \\
55 \cdot 70\end{array}$ & $\begin{array}{c}\text { Per cent. } \\
\ldots\end{array}$ & $\begin{array}{c}\text { Per cent. } \\
\ldots\end{array}$ \\
\hline Steel forging . & - & . & $12 \cdot 50$ & 14 & $28 \cdot 56$ & 18 & 37 \\
\hline
\end{tabular}


The specimens used in the reversals experiments were of the form shown in Fig. 14. It will be seen that these were provided with screwed ends to fit the tensile dies, and they had centres to receive the steel balls when loaded in comFig. 14. pression. The bars were all turned to a diameter of 0.798 inch, giving an area of cross section of 0.500

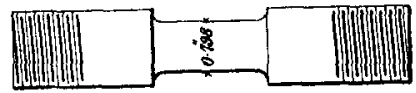
square inch.

In carrying out the experiments the bar was first loaded in tension to somewhere near the primitive limit, previously found. The load was then removed gradually and an equal load applied in compression. This cycle was repeated ten times, with the result that two artificial limits were established, one in tension and one of an equal value in compression.

The same process was repeated on the same bar with an applied load somewhat higher than the last, and in this way a second artificial limit (A.L.) was found. The kind of curves obtained is shown on Fig. 15. Mr. L. Bairstow, when experimenting on bars which had been subjected to repeated reversals in a repetition of stress machine, obtained very similar curves. ${ }^{1}$

The operations described above were repeated several times, the load being raised in each successive experiment, and in this way a series of artificial limits was found for the one material. The results of this determination in the case of two bars of cast steel are given in the following Table:-

Artificial Limit Stresses for Two Bars of Cast Steet.

\begin{tabular}{|c|c|c|}
\hline Bar. & $\begin{array}{l}\text { Applied Stresses. } \\
\text { Tension and } \\
\text { Compression. }\end{array}$ & $\begin{array}{l}\text { Corresponding } \\
\text { Artiflcial Limit } \\
\text { Stresses. }\end{array}$ \\
\hline No. 3 & $\begin{array}{c}\text { Tons per Square Inch. } \\
20^{\circ} 00\end{array}$ & $\begin{array}{l}\text { Tons per Square Inch. } \\
\quad 18 \cdot 00\end{array}$ \\
\hline$"$ & $21 \cdot 00$ & $9 \cdot 00$ \\
\hline , & $22 \cdot 00$ & $5 \cdot 50$ \\
\hline No. 4 & $20 \cdot 50$ & $15 \cdot 75$ \\
\hline ,. & $21 \cdot 50$ & $8 \cdot 50$ \\
\hline ," & $22 \cdot 50$ & $5 \cdot 50$ \\
\hline ., & $22 \cdot 75$ & $4 \cdot 50$ \\
\hline
\end{tabular}

' "Elastic Limits of Iron and Steel under Cyclical Variations of Stress," Phil. Trans. Royal Society, 1909, vol. 210. 
These results are plotted on Fig. 16 , and the method adopted will be clear from an inspection of the Figure. The applied stresses are plotted vertically from $O A$ and the corresponding artificial limits from $O B$, to the same scale. The line $O C$ is drawn at $45^{\circ}$ with

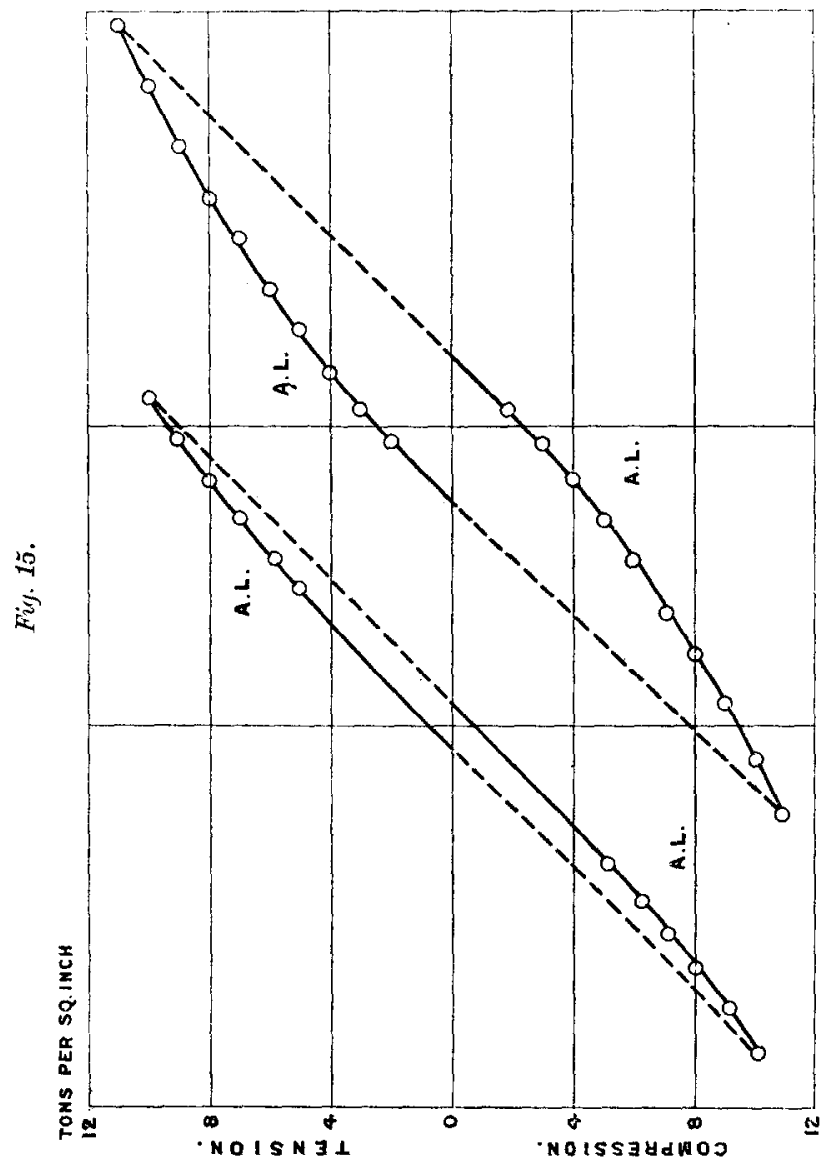

$O A$ and $O B$, so that any point in it has the same value for the applied stress and for the artificial limit. The artificial limits given in the above Table are plotted for the two bars and a smooth curve drawn through the points to cut $O C$. At the point $D$ so obtained, the artificial limit has the same value as the applied load - that is to say, there is no artificial limit observable less than the applied loads. 
The Author suggests that the point so obtained for a given material points to a limiting stress for an infinite number of repeated reversals of equal stresses. In the present case it may be taken as having a value of 20.25 in either direction, or a range of stress of twice this value, or 40.50 tons per square inch. This is based on the assumption that if a material has been subjected to a number of reversed stresses, and it is found that on reimposition of the stress there is no permanent disturbance visible, the material

Fig. 16.

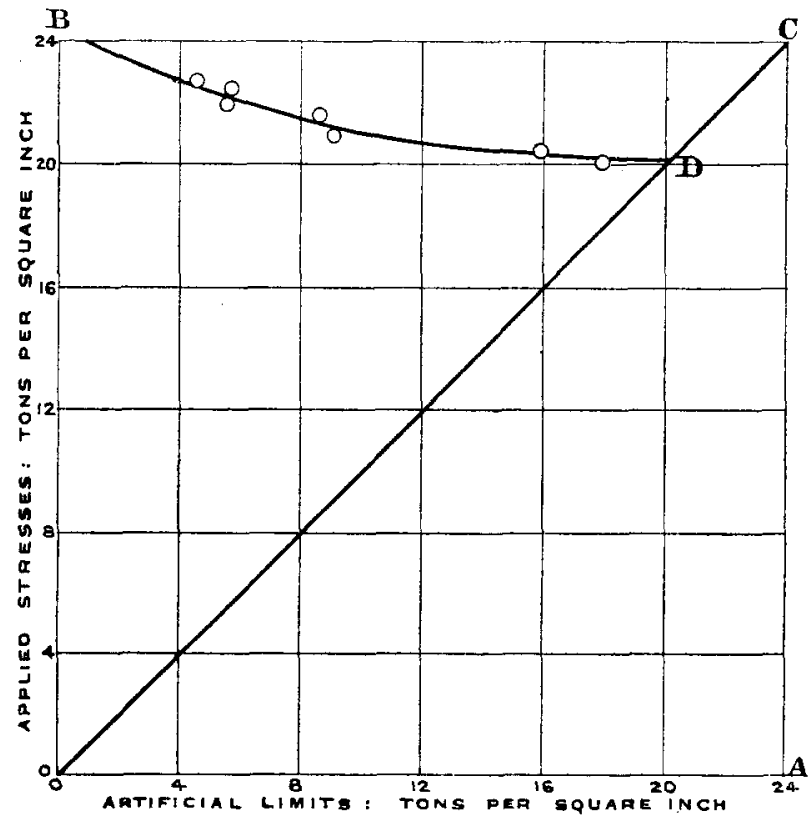

will be capable of withstanding an unlimited number of such impositions of the same stresses.

The values for the steel forging are plotted on Fig. 17, in a manner similar to the points on Fig. 16. It will be seen that a smooth curve drawn through the plotted points cuts the line OC at the point $\mathrm{D}, 9 \cdot 20$ tons per square inch, representing a total range of $18 \cdot 40$ tons per square inch.

The same results might have been attained by similar experiments on several bars of the same material, using a different bar for each applied load; the Author has tried both methods for the 

same material, and has found that they give practically the same

Fig. 17 .

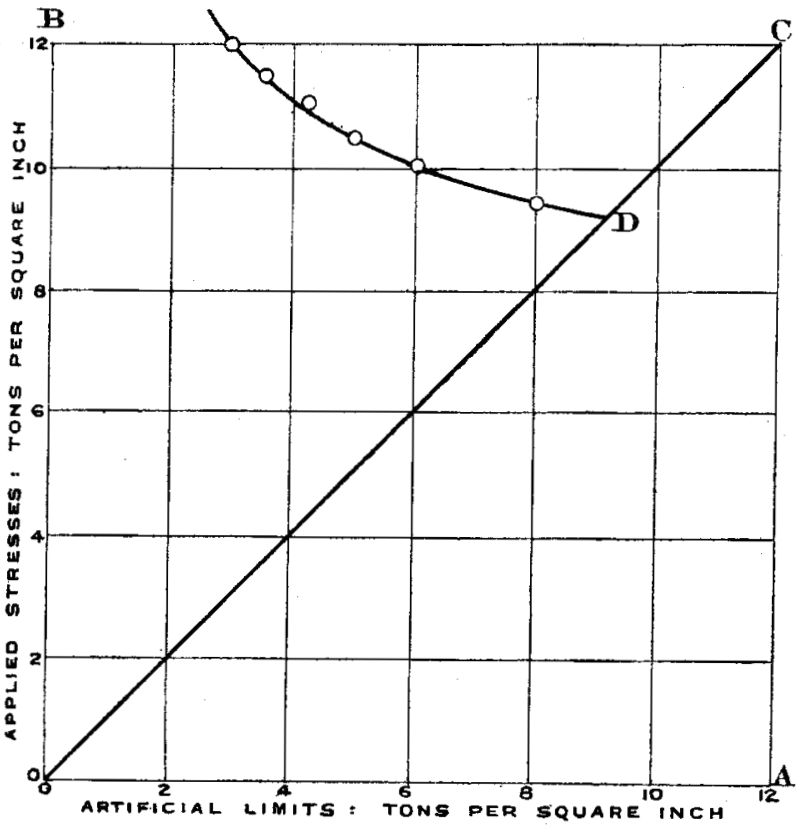

results, so long as the single-bar experiments are carried out with increasing applied loads.

Artificial Limit Stresses for Steet Forgivg.

\begin{tabular}{|c|c|c|c|}
\hline \multicolumn{2}{|c|}{ Bar. } & $\begin{array}{l}\text { Applied Stresses. } \\
\text { Tension and }\end{array}$ & $\begin{array}{l}\text { Corresponding } \\
\text { Artificial Limit }\end{array}$ \\
\hline \multicolumn{2}{|c|}{ Steel forging } & $\begin{array}{l}\text { Tons per Sq. In. } \\
\quad 9 \cdot 50\end{array}$ & $\begin{array}{c}\text { Tons per Sq. In. } \\
8^{\circ} 00\end{array}$ \\
\hline " & , & $10 \cdot 00$ & $6 \cdot 00$ \\
\hline ", & ", & $10 \cdot 50$ & $5 \cdot 00$ \\
\hline$"$ & , & $11 \cdot 00$ & $4 \cdot 25$ \\
\hline ", & " & $11 \cdot 50$ & $3 \cdot 50$ \\
\hline " & , & $12 \cdot 00$ & $3 \cdot 00$ \\
\hline
\end{tabular}




\section{Running or Enderance Experiments.}

It was necessary to be able to compare the above results with limiting stresses obtained from actual repetitive tests at speeds comparable with those employed in practice and carried to the point of fracture. In the absence of a direct-stress repetitive machine, the Author employed the rotating beam as being the most convenient method.

The scheme of the machine used is shown in Fig. 18. It consists of two adjustable ball-bearings attached to a rigid frame at

Fig. 18.

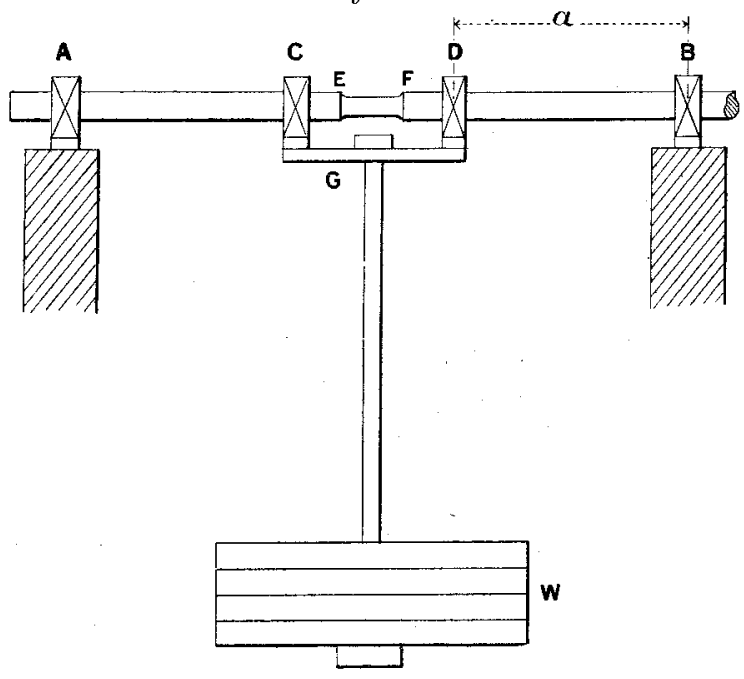

$A$ and $B$; in these bearings ran the test specimen, a bar $\frac{7}{8}$ inch diameter for the greater part, but reduced gradually to $\frac{1}{2}$ inch diameter at the middle of $\mathbf{E F}$.

The specimen passes through another pair of ball-bearings at $\mathrm{C}$ and $\mathrm{D}$, these being attached to the frame $\mathrm{G}$, which supports the load W. In all four bearings the balls run in spherical races, so that the specimen is quite free to bend when and how it likes. Rotation of the specimens is effected by means of a lathe-carrier and a face-plate fixed to a shaft running in separate bearings; by this arrangement the bending effect due to belt pull is avoided. 
The downward pull of the load causes a bending moment between $\mathrm{C}$ and $\mathrm{D}$, constant in value, and equal to--

$$
\frac{W}{2} \times a=\frac{W}{2} \times 7 \frac{1}{2}(\text { inch-lbs. })
$$

This bending moment was also equal to $f \frac{d^{3}}{32}$, where $f$ is the maximum stress in the material due to the bending, and $d$ the diameter of the bar at its smallest diameter.

That is-

$$
\begin{aligned}
f & =305 \mathrm{~W} \text { (lbs. per square inch). } \\
& =\frac{\mathrm{W}}{7 \cdot 344} \text { (tons per square inch). }
\end{aligned}
$$

In carrying out experiments on this machine, the load was first adjusted so as to give a stress in the material somewhat higher than the limiting stress which had been predicted by the experiments already described. The machine was then started and allowed to run steadily at a speed of about 350 revolutions per minute. A counter was attached to the specimen and also an automatic stop arrangement, so that the machine could go on running until fracture took place. In these experiments the machine ran during the day only, and had to stop during meal hours, and at the week-end.

When fracture occurred to a specimen it was taken out of the machine and a new one started under an increased or decreased load. If the machine had run to one million revolutions or over, the new load was larger than the last, and the contrary if the bar had broken after a comparatively small number of revolutions, the object being to get a more or less complete series of results for all stresses.

The results for cast steel were as follows :-

Running-Tests of Cast Steerl.

\begin{tabular}{|c|c|c|}
\hline w. & Stress $f$. & Revolutions up to Fracture, $n$. \\
\hline Lbs. & Tons per Sq. In. & \\
$200 \cdot 0$ & $27 \cdot 2$ & 15,580 \\
$190 \cdot 0$ & $25 \cdot 9$ & 162,600 \\
$185 \cdot 0$ & $25 \cdot 2$ & 214,000 \\
$180 \cdot 0$ & $24 \cdot 5$ & 377,780 \\
$180 \cdot 0$ & $24 \cdot 5$ & 417,780 \\
$177 \cdot 5$ & $24 \cdot 2$ & 781,000 \\
$177 \cdot 5$ & $24 \cdot 2$ & $2,000,000$ (not broken) \\
$175 \cdot 0$ & $23 \cdot 9$ & 468,260 \\
$175 \cdot 0$ & $23 \cdot 9$ & $2,425,720$ (not broken) \\
$175 \cdot 0$ & $23 \cdot 9$ & 923,680 (not broken) \\
\hline
\end{tabular}


Papers.] AND THE ULTIMATE ENDURANCE OF STEEL.

The results given in the above Table are shown plotted on Fig. 19. Of the two curves shown, one is drawn through points representing values of $\mathrm{W}$ plotted as ordinates, and the number of revolutions up to fracture, $n$, as abscissas; and in the other the ordinates $W$ are plotted with $1 / n$ as abscissas. The first curve is similar to stressrepetition curves obtained by Wöhler and all later experimenters, and presents the usual indefiniteness as to the height of the horizontal tangent.

In the case of the $1 / n$ curve, a smooth curve drawn through the

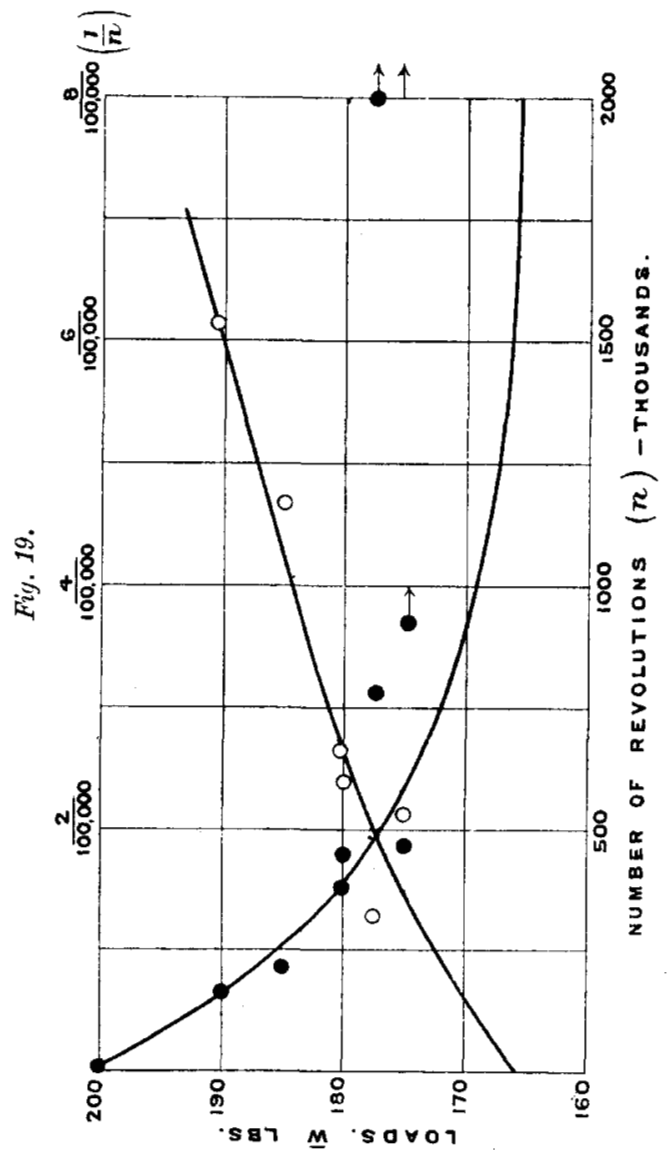

plotted points cuts the vertical, where $1 / n$ is zero, at a point where $\mathrm{W}=165 \mathrm{lbs}$. The stress corresponding to this is

$$
f=\frac{165}{7 \cdot 344}=22 \cdot 40 \text { tons per square inch, }
$$


which is equivalent to a range of stress of $44 \cdot 80$ tons per square inch. This limiting stress of $22 \cdot 40$ tons per square inch is higher than the limiting stress of $20 \cdot 25$ tons per square inch suggested by the static experiments.

The results of the running-tests on the steel forging are given

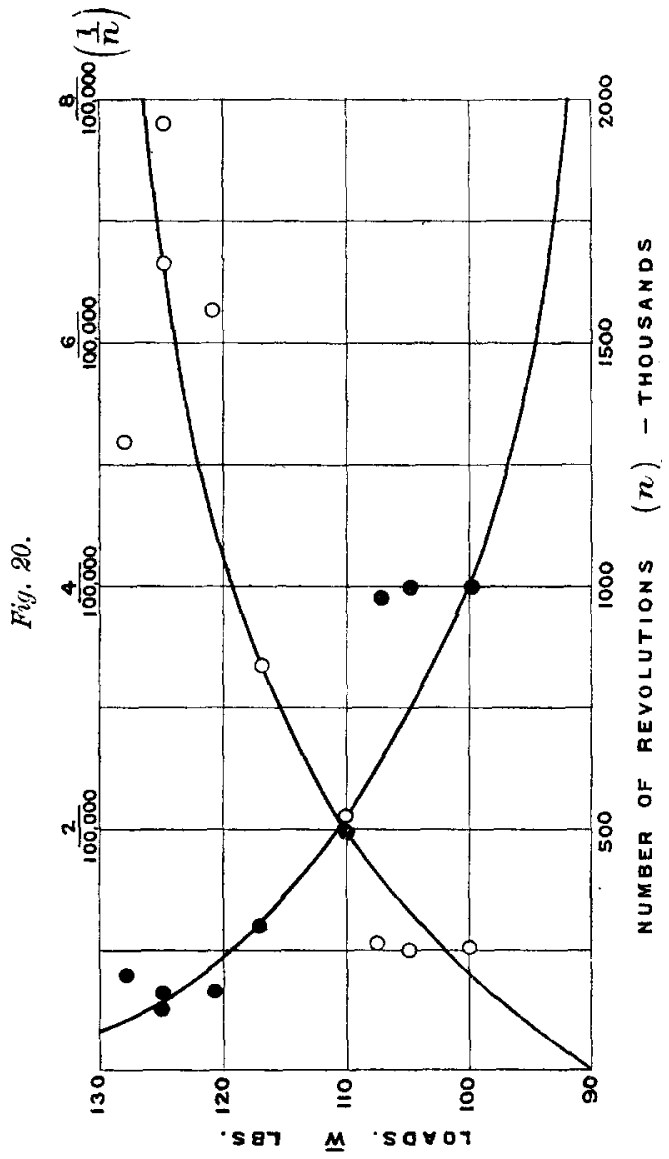

below. The experiments were carried out in precisely the same way as those with the cast steel. These results are plotted on Fig. 20 , and it will be seen that the $1 / n$ curve cuts the line of loads at $90 \mathrm{lbs}$., corresponding to a stress of $12 \cdot 20$ tons per square inch, or a range of $24 \cdot 40$. The difference between this limiting stress and the estimated stress of $9 \cdot 2$ tons per square inch is more marked than in the case of the cast steel. 
In both cases, therefore, the endurance or running-tests gave results which are higher than those given by the static tests, but the conditions of application of stress were, in two important respects, different.

Runving-Tests of Steel Forging.

\begin{tabular}{|c|c|c|}
\hline w. & Stress $f$. & $\begin{array}{c}\text { Revolutions } \\
\text { to } \\
\text { Fracture. }\end{array}$ \\
\hline $\begin{array}{c}\text { Lbs. } \\
128 \cdot 5\end{array}$ & $\begin{array}{c}\text { Tons per. } \\
\text { Square Ineh. } \\
17 \cdot 5\end{array}$ & $\begin{array}{c}\text { No. }(n) . \\
. .\end{array}$ \\
\hline $128 \cdot 5$ & $17 \cdot 5$ & 192,380 \\
$125 \cdot 0$ & $17 \cdot 0$ & 128,046 \\
$125 \cdot 0$ & $17 \cdot 0$ & 150,780 \\
$121 \cdot 0$ & $16 \cdot 5$ & 159,480 \\
$117 \cdot 0$ & $15 \cdot 9$ & 301,620 \\
$110 \cdot 0$ & $15 \cdot 0$ & 480,460 \\
$107 \cdot 5$ & $14 \cdot 6$ & 970,440 \\
$105 \cdot 0$ & $14 \cdot 3$ & $1,003,750$ \\
$100 \cdot 0$ & $13 \cdot 6$ & $1,000,602$ \\
\hline
\end{tabular}

In the static tests, the applied stresses were substantially uniform over a cross section of the bar; whereas in the running-tests the distribution was that which occurs in the middle of a loaded beam, where the intensity varies from a maximum compressive at the upper surface to zero at the centre, and increasing again uniformly to a maximum tensile stress at the lower surface.

It has been shown in previous repetitive tests, where the same material has been subjected to both direct stress and to repeated bendings, that the latter condition always gives higher results than the former, for reasons which have not yet been made clear. The Author had no means of carrying out experiments at higher speeds with direct stresses, and had to be content with the rotating beam.

A vast number of endurance tests have been published, but it has been extremely difficult to find figures with which to compare the present results. Of these the figures in the following Table are the nearest. 


\begin{tabular}{|c|c|c|c|c|c|c|c|}
\hline Authority. & Material. & Primitive & $\begin{array}{l}\text { Yield } \\
\text { Point. }\end{array}$ & T'enacity. & $\begin{array}{l}\text { Limiting } \\
\text { Stress. }\end{array}$ & $\begin{array}{l}\text { Pange of } \\
\text { Stress. }\end{array}$ & Metal. \\
\hline & & $\begin{array}{l}\text { Tons per } \\
\text { St. In. }\end{array}$ & $\begin{array}{l}\text { Tons per } \\
\text { Sil. In. }\end{array}$ & $\begin{array}{l}\text { Tous per' } \\
\text { Sq. In. }\end{array}$ & $\begin{array}{c}\text { Tons per } \\
\text { S'L. In. }\end{array}$ & $\begin{array}{l}\text { Tons per } \\
\text { Sq. Tn. }\end{array}$ & \multirow{3}{*}{$\begin{array}{c}\text { Quick } \\
\text { rotating } \\
\text { bean. } \\
\text { Slow } \\
\text { testing- } \\
\text { machine. }\end{array}$} \\
\hline Author & $\left\{\begin{array}{c}\text { Steel } \\
\text { forging }\end{array}\right\}$ & $12 \cdot 50$ & $14 \cdot 00$ & 2856 & $12 \cdot 20$ & $24 \cdot 40$ & \\
\hline " & $"$ & $12 \cdot 50$ & $14 \cdot 00$ & $28 \cdot 56$ & $9 \cdot 20$ & $18 \cdot 40$ & \\
\hline $\begin{array}{c}{ }^{1} \text { Stanton } \\
\text { and } \\
\text { Bairstow }\end{array}$ & $\left.\begin{array}{c}\text { Steel } \\
\text { forging }\end{array}\right\}$ & $12 \cdot 94$ & $14 \cdot 52$ & $29 \cdot 47$ & . & $20 \cdot 60$ & $\left\{\begin{array}{c}\text { Quick } \\
\text { direct } \\
\text { stress. }\end{array}\right.$ \\
\hline
\end{tabular}

It may not be strictly fair to make a comparison between Messrs. Stanton and Bairstow's figures and those of the Author, but it is interesting to note that the Author's rotating beam figure is higher than that of Stanton's direct stress, which is to be expected in the case of two specimens of the same material tested in the two different ways. From this it may be argued that the Author's figure of $24 \cdot 4$ is too high.

Taking these facts into consideration, and remembering also that the endurance results quoted are for one million or two million reversals and not for an unlimited number, the Author thinks it reasonable to suppose that his figures, obtained from the Bauschinger method, may be not far below the true values for an unlimited number of reversals.

A point of similarity between the Stanton and Bairstow results and those of the Author is to be found in the fact that in all cases the ultimate limiting stresses are lower than the primitive limits.

\section{Conclusions.}

The experiments on the steel forging and the tool steel whose results have been discussed have been selected from many others, mostly on mild steel, as being representative and typical. The conclusions to be drawn from these experimental results seem to be those given below. In examining them it must not be forgotten that their bearing is restricted to the case in which the imposed stresses are alternately tensile and compressive and of equal intensity.

1. The application of a number of alternating stresses of equal intensity, from near the primitive limit to somewhere below the

1 T. E. Stanton and L. Bairstow, "On the Resistance of Iron and Steel to Reversals of Direct Stress," Minutes of Proceedings Inst. C.E., vol. clxvi 1906, p. 78. 
yield-point of steel, develops artificial limits which have the same value in tension and compression.

2. Equal applied stresses result in equal artificial limits.

3. Higher applied stresses result in lower artificial limits.

4. By plotting a number of the artificial limits corresponding to different applied stresses for the same bar, and drawing a smooth curve through these, it is possible to find a stress in which the artificial limit and the applied stress are coincident.

5. Experiments up to fracture with rotating beams lead to the opinion that the limiting stress in (4) is not far remored from the stress which the metal in question may be expected to sustain without fracture for an unlimited number of reversals of equal stresses.

The limiting stress in (4) is probably the same as found by. Bauschinger by gradually diminishing his applied stresses. Bauschinger did not, however, carry his experiment to the extreme end, but stopped at an artificial limit (called by him the "natural limit") which was probably somewhat higher than the limiting stress.

The Author ventures to suggest that the limiting stress for a very large number of reversals of equal stresses might be predicted with sufficient nearness for practical purposes by means of experiments similar to those which have been described.

The method would be somewhat as follows :-

(a) A sample of the material in question would be loaded in a testing machine, and elastic readings taken to give the primitive limit and the yield-point stresses.

(b) A new bar of the same material would be taken and subjected to ten reversals of stress just below the primitive limit.

(c) Following this, the new limits in tension and compression would be determined.

(d) (b) and (c) to be repeated under increasing stresses, the difference between each succeeding applied stress being so arranged that there would not be fewer than six between the primitive limit and the yield stress.

(e) The values of all the artificial limits so found would have to be plotted against the applied stresses and a smooth curve drawn through the points so obtainod. Where this curve intersected the line of equal applied stress, the corresponding artificial limit should give the limiting stress required.

It is possible that this method might be extended to cases of [THE INST. O.E. VOL. CXCVII.] 
stresses between limits which are not equal, that is, from a certain tension to a certain compression.

The process described is less tedious than the carrying out of endurance tests to destruction, and so far there appears to be no reason to suppose that the results attained would be less reliable.

The Author desires to express his acknowledgments to the governing body and the Principal of the Manchester School of Technology for the facilities afforded for obtaining the results given ; and to Mr. J. T. Hodgson, head of the Works Department, and Mr. W. Liversedge for valuable help and many useful suggestions.

The Paper is accompanied by fourteen tracings, from which the Figures in the text have been prepared. 